\title{
Multiscale friction model for hot sheet metal forming
}

\author{
Jenny VENEMA ${ }^{1, *}$, Javad HAZRATI ${ }^{2}$, Eisso ATZEMA ${ }^{1}$, David MATTHEWS ${ }^{3}$, Ton van den BOOGAARD $^{2}$ \\ ${ }^{1}$ Tata Steel, Research \& Development, CA Ijmuiden 1970, the Netherlands \\ ${ }^{2}$ Nonlinear Solid Mechanics, Faculty of Engineering Technology, University of Twente, Enschede 7522 NB, the Netherlands \\ ${ }^{3}$ Laboratory for Surface Technology and Tribology, Faculty of Engineering Technology, University of Twente, Enschede 7522 NB, the \\ Netherlands
}

Received: 15 October 2020 / Revised: 28 January 2021 / Accepted: 02 March 2021

(C) The author(s) 2021.

\begin{abstract}
The accurate description of friction is critical in the finite element (FE) simulation of the sheet metal forming process. Usually, friction is oversimplified through the use of a constant Coulomb friction coefficient. In this study, the application of an existing multiscale friction model is extended to the hot stamping process. The model accounts for the effects of tool and sheet metal surface topography as well as the evolution of contact pressure, temperature, and bulk strain during hot stamping. Normal load flattening and strip drawing experiments are performed to calibrate the model. The results show that the model can relatively well predict friction in strip draw experiments when the tool surface evolution due to wear is incorporated. Finally, the application of the formulated multiscale friction model was demonstrated in the FE simulation of a hot-stamped part.
\end{abstract}

Keywords: tribology; wear; friction; hot stamping; friction model

\section{Introduction}

Hot stamping is used in the automotive industry to produce high-strength structural parts. In this process, a sheet metal blank is heated in a furnace, formed at high temperature values $\left(600-800{ }^{\circ} \mathrm{C}\right)$, and quenched in the press to obtain a high-strength part with satisfactory geometrical tolerance. To prevent scaling during austenitization and provide corrosion protection to the end-product, the hot-stamped steel is usually coated with Al-Si alloy.

Finite element (FE) simulations are currently used in the metal forming industry for feasibility analyses and process parameter optimization. To accurately predict the stresses and strains, the material and friction behaviors in these FE models should be precisely described. The material behavior of hot-stamped steels has been previously investigated extensively $[1,2]$. However, the description of friction in the FE simulations of hot stamping processes is usually oversimplified by the use a constant Coulomb friction coefficient (COF) [1, 3-5]; consequently, the actual conditions are not well represented. The description of these conditions is the focus of this study.

Friction models have been developed and applied to several forming processes at elevated temperatures. For example, Stupkiewicz and Mróz [6] developed a three-body contact model that describes friction in hot metal forming. The oxide scale is represented by hard third-body particles embedded in the workpiece surface layer. The model is derived from a micromechanical model involving the interaction of particles with a hard tool surface and soft workpiece interface. Wang [7] developed a friction model for aluminum extrusion. In this model, the strength of the adhesive junction is determined by two factors: rate of atomic interaction and strength of adhesive joints. Another approach is to create a database of

* Corresponding author: Jenny VENEMA, E-mail: jenny.venema@tatasteeleurope.com 
COFs that are integrated into commercial FE software codes using a phenomenological model. This approach has been investigated for hot stamping in the FOSTA P871 project [8]. The model is a function of temperature, pressure, and velocity [8]; however, this approach does not consider the effect of tool and sheet surface topography on the COF. Furthermore, a database must be constructed for every specific tool and sheet material combination.

To increase the accuracy of describing friction in deep drawing simulations at room temperature, Hol et al. [9] formulated a multiscale friction model. The model accounts for the micromechanical friction mechanisms that occur in cold stamping processes. Furthermore, the surface asperities are modeled by bars and statistical parameters [10], and the COFs are calculated in several steps. First, the real contact area is determined by accounting for the asperity deformation due to normal loading, bulk deformation [10], and sliding [11]. Subsequently, the shear stresses between the solid-to-solid contact and the corresponding COFs are calculated [12, 13].

To date, several studies have attempted to explain the friction mechanisms of Al-Si-coated hot stamping steel through the adhesion and plowing phenomena [14-16]. Several tribological interactions have been identified between the tool and Al-Si-coated presshardening steel (PHS) during sliding [17]. These include (a) initial contact, (b) tool plowing through coating, (c) secondary plowing in the blank material by the adhered material on the tool, and (d) plowing in the tool by the embedded particles in the sheet.

In hot stamping, lubrication is not applied, and the load is borne by the surface asperities in contact. Therefore, determining the actual contact area is critical. The real contact area evolves because of the normal loading, bulk deformation, and sliding [18]. In the models representing the foregoing, the contact between a hard perfectly flat surface and a soft rough surface is usually assumed. A soft rough surface may deform elastically, plastically, or in combination. Greenwood and Williamson [18] developed a stochastic contact model for spherically shaped summits. Since then, researchers have modified and extended the application of contact models. For example, arbitrarily shaped asperities [10, 19], plastically deforming asperities [20], bulk deformation [21, 22], asperity interactions [10, 23], and coating [24] have been employed. Other techniques for describing the flattening behavior are based on variational principles [25] or FE simulations [26].

Sliding causes an additional tangential load on asperities. Tabor [11] stated that this additional load has to result in an increase in the real contact area because a constant von Mises stress has to be maintained at the contact points that have yielded. This increase, called junction growth, has been measured by several researchers [27-29].

Friction is caused by the plowing and adhesion of two contacting surfaces. Wilson [30] formulated a friction model in which plowing and adhesion were separately treated. Challen and Oxley $[12,31]$ derived equations for the $\mathrm{COF}$ in three regimes using slip-line field analysis. To calculate the total COF, a translation must be made from a single asperity scale to a multiple asperity scale. Multiple tool asperities plow through the soft rough sheet coating. However, instead of individual tool asperities, contact patches were formed; these patches were described by Ma et al. [13].

In this work, the application of an existing multiscale model [9] is extended to hot stamping by incorporating the effects of the coating layer into the contact model [24]. A temperature-dependent material model, formulated by Abspoel et al. [1] for the substrate, was also included. Further, a phenomenological temperature-dependent and pressure-dependent interfacial shear strength model was implemented. For calibrating the multiscale friction model, hot friction tests (HFTs) are performed. The friction model is implemented in an FE simulation, and the FE predictions are compared with the experimental results of a top-hat product. The multiscale friction model may be utilized to comprehend the friction mechanisms and effects of different process parameters in hot stamping.

The remainder of this paper is organized as follows. Section 2 outlines the experimental setup and explains the experimental results relevant to the friction model. Section 3 discusses the multiscale model whose formulation is divided into three model steps. Section 4 elaborates on the implementation of the friction model in the FE simulation of the fabrication 
a top-hat product. Section 5 discusses the results, and the last section summarizes the conclusions and recommendations.

\section{Experimental}

Three sets of experiments are performed, as shown in Fig. 1. First, normal loading tests were conducted to validate the normal load contact model. Second, HFTs are performed to calibrate the junction growth and interfacial shear strength models. Finally, the top-hat products are hot-stamped to demonstrate the application of the complete multiscale friction model in the FE simulation of the hot stamping process.

Imaging analysis was performed on the sheet metal and tools. Three-dimensional (3D) optical (nanofocus $\mu$ surf mobile) topographical measurements were conducted to investigate the friction and wear mechanisms and determine the real contact area after the test. Cross-sectional analysis by optical microscopy (Leica DM-LM microscope with a motorized stage and camera) was performed to investigate the coating fracture.

Al-Si(7-11 wt\% Si)-coated PHS was used in the experiments. All the tests were performed on a hot stamping facility at Tata Steel. The blank was heated for $6 \mathrm{~min}$ in a roller hearth furnace at $930^{\circ} \mathrm{C}$. Thereafter, the blank was transported to either the hot friction test unit or stamping press.

\subsection{Setup}

\subsubsection{Normal loading test and HFT}

Normal loading tests and HFTs were performed on the same installation. After the heat treatment, the strip $(800 \mathrm{~mm} \times 50 \mathrm{~mm} \times 1.5 \mathrm{~mm})$ was automatically transferred to the test unit. The strip temperature was measured using a pyrometer (SN21 LAND SOLOnet). The test started when the specified start temperature on the sheet was attained. In the normal loading tests, the tools were closed when the specified temperature was attained $\left(500-800{ }^{\circ} \mathrm{C}\right.$ at $100{ }^{\circ} \mathrm{C}$ intervals), and normal pressure values of 5,10 , or $20 \mathrm{MPa}$ were applied for $5 \mathrm{~s}$. In the HFT, the tools were closed at start temperatures of $450-750{ }^{\circ} \mathrm{C}$ (at $50{ }^{\circ} \mathrm{C}$ intervals). The strip was drawn by the tool at a velocity of $100 \mathrm{~mm} / \mathrm{s}$ over a $220-\mathrm{mm}$ distance at pressure values of $2.5,5$, or $10 \mathrm{MPa}$; for each test setup, a new tool set was used. The classical Coulomb law was applied to calculate the $\mathrm{COF}(\mu)$ :

$$
\mu=\frac{F_{t}}{2 \cdot F_{n}}
$$

where $F_{\mathrm{t}}$ and $F_{\mathrm{n}}$ are the traction force and normal load applied to the strip surface, respectively.

More information on the experiments can be found in Refs. [17, 32]. The tools for the HFT and normal loading test are rectangular (flat tool surface: $90 \mathrm{~mm} \times$ $11 \mathrm{~mm})$; they have a tool roughness $(S a)$ of $0.20 \pm$ $0.05 \mu \mathrm{m}$. The tools for the normal loading tests and hot strip drawing are made from tool steels used in several hot forming application areas. Tool steels DIN 1.2367 and DIN 1.2344, hardened to 55 and $48 \pm$ 2 HRC, were used for the normal loading tools and hot strip drawing tools, respectively. The tools were not preheated.

\subsubsection{Top-hat product}

In the top-hat experiment, the blank $(350 \mathrm{~mm} \times$ $250 \mathrm{~mm} \times 1.51 \mathrm{~mm}$ ) was transported to the press (in $\sim 7 \mathrm{~s}$ ) after austenitization and positioned on four distance pins. The blank was formed as soon as the temperature reached $700{ }^{\circ} \mathrm{C}$. A spacer distance of $1.65 \mathrm{~mm}$ was applied between the blank holder and die, which hold the sheet without applying any normal force. The drawing velocity was $100 \mathrm{~mm} / \mathrm{s}$, and the drawing height was $50 \mathrm{~mm}$. A schematic of the product
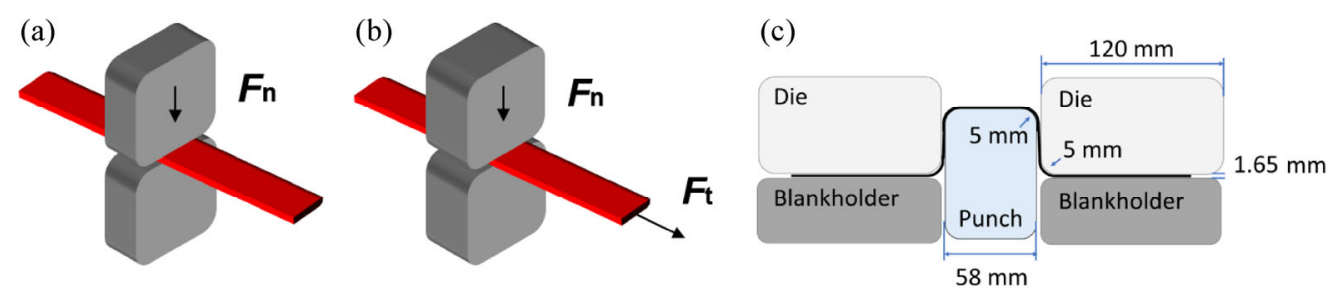

Fig. 1 Schematic of experiments: (a) normal load test, (b) HFT, and (c) hot stamping of top hat. 
with its dimensions is shown in Fig. 1(c). The tools were made of DIN 1.2344 hardened to 48 HRC. Lubrication was not applied to the sheet or die. The die was new, and the punch was relatively clean. Confocal measurements of the tools were performed at the radius performed before drawing, after 5 strokes, and after 50 strokes.

\subsection{Experimental results}

\subsubsection{Normal loading}

The application of a normal load flattened the coating through plastic deformation and fracture of surface asperities. As shown by the optical cross-sections in Fig. 2, the voids underneath the surface are crushed. Figure 2 further shows that the fractured particles not only fill the valleys but also remain on the surface in contact with the tools. Hence, the fractured particles may also possibly bear a certain amount of load.

The multiscale friction model calculated the fractional real contact areas, which had to be measured to validate the model. The surface topography of the sheet was measured at two locations: reference position and loaded position. Height distribution curves are obtained from the measured topographies, as shown in Fig. 3. The fractional real contact area can be determined from the undeformed and deformed height distribution curves [9]. This area is determined by summing the probability of the heights (asperities) that are flattened by the tool (right side of upper or lower bound in Fig. 3(a)) and dividing this sum by the total sum of probabilities in the undeformed curve. In the ideal case, a vertical line is observed in the loaded height distribution curve, indicating the deformation location. However, a finite slope is visible in the curve because the asperities are elastically deformed, the tool surface is not perfectly flat, and the asperities are fractured. Hence, a range of values was determined for the fractional real contact area. The upper bound is the local top point, and the lower bound is the point at which the slopes increase (Fig. 3(a)). The upper and lower bounds (yellow points in Fig. 3(a)) are visually identified. The fractional real contact areas between 0.005 and 0.054 were calculated at different contact pressures and temperatures. In disregarding one outlier (at $700{ }^{\circ} \mathrm{C}$ and $20 \mathrm{MPa}$ ), the higher pressure and temperature values resulted in a larger real contact area (which is expected), as shown in Fig. 3(b).

\subsubsection{Hot friction draw test}

In the hot friction draw test, adhesive wear immediately accumulates on the tool surface in the first draw [17]. In the initial state, the tool plows through the hills of the sheet and flattens its profile, as shown in Fig. 4(b). These effects were observed when the sheet was in contact with a clean tool in which no adhesive wear was present. As soon as the adhesive wear accumulated on the tools, the material that had adhered plowed through the relatively soft (a)

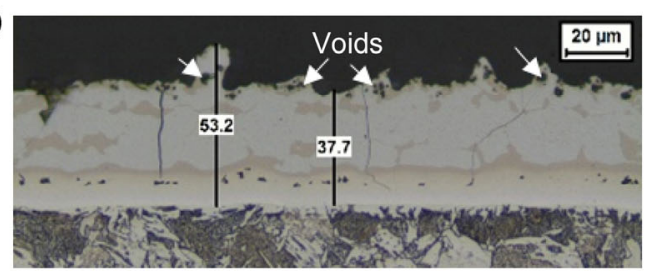

(b)
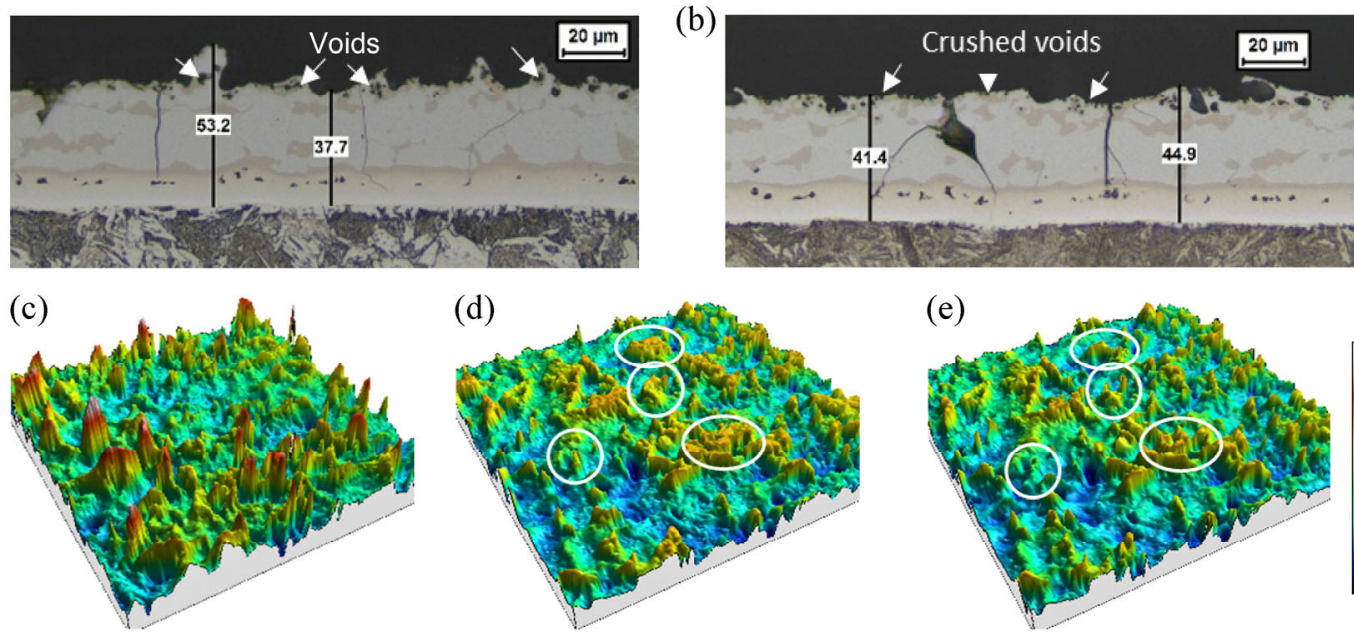

(d)

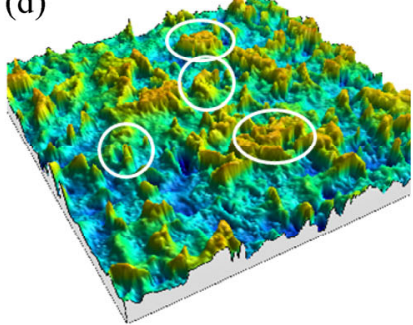

(e)

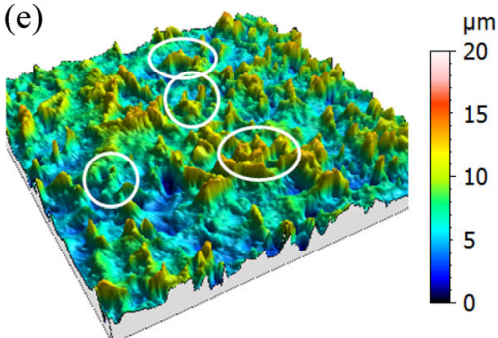

Fig. 2 Optical cross-sections of coating at (a) reference state and (b) after normal loading; confocal measurement $(0.3 \mathrm{~mm} \times 0.3 \mathrm{~mm})$ of sheet surface for (c) reference state, (d) after loading including fractured particles, and (e) after loading without fractured particles. Normal load experiments are performed at $700{ }^{\circ} \mathrm{C}$ and contact pressure of $20 \mathrm{MPa}$. 

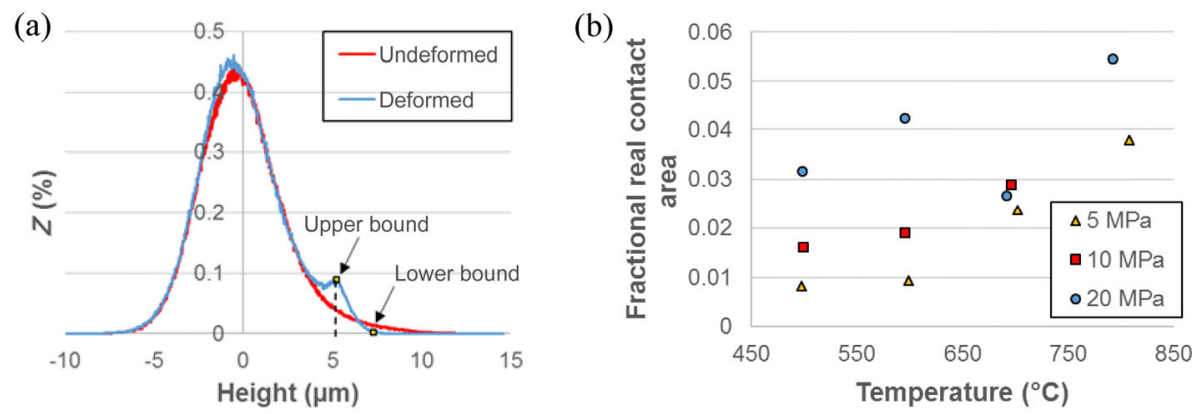

Fig. 3 (a) Height distribution curves of undeformed and deformed surfaces (after normal loading) used to determine fractional real contact area (at $20 \mathrm{MPa}$ contact pressure and $500{ }^{\circ} \mathrm{C}$ ); (b) fractional real contact area (upper bound points) versus temperature at 5, 10, and $20 \mathrm{MPa}$ contact pressure.

(a)

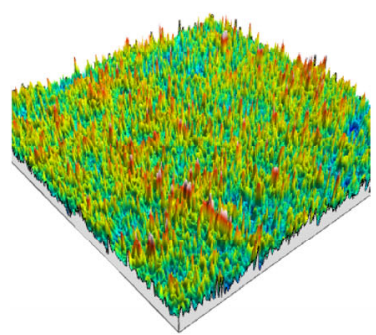

(b)

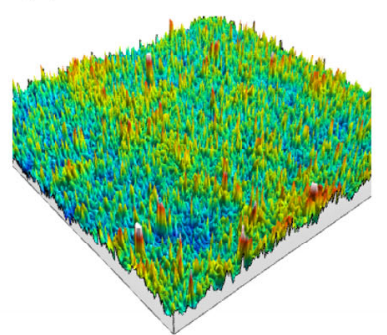

(c)

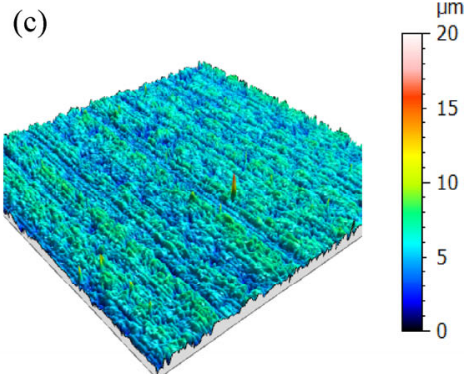

Fig. 4 Confocal measurements $(2 \mathrm{~mm} \times 2 \mathrm{~mm})$ of strip surface at $700{ }^{\circ} \mathrm{C}$ and $5 \mathrm{MPa}$ : (a) after heat treatment, (b) tool plows through hills and flattens profile, and (c) secondary plowing by adhesive wear on tool.

sheet coating. This plowing results in tracks on the sheet with a depth of approximately $5 \mu \mathrm{m}$, as shown in Fig. 4(c).

In the experiments, the COF virtually becomes independent of the temperature after a certain number of strokes; however, the tool wear is temperaturedependent [32]. For each temperature value, confocal measurements of the tool were performed after 10 slides. At lower temperature values $\left(<600{ }^{\circ} \mathrm{C}\right)$, adhesive wear covered a large area of the tool. At higher temperature values $\left(>600^{\circ} \mathrm{C}\right)$, abrasive wear and adhesive wear were both visible. Detailed experimental results can be found in Ref. [32].

\subsubsection{Top hat product}

The top-hat experiments showed that tool wear is one

(a)

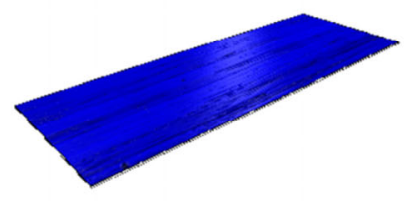

(b)

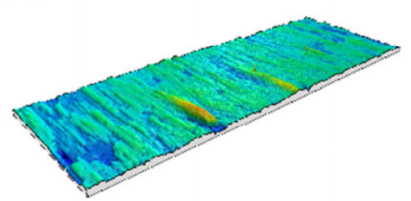

of the predominant factors in hot stamping. Scratches occur on the wall of the top-hat product owing to the adhesive wear on the tool. These scratches are already visible in the first product. After further repetitions, galling on the tool becomes more severe, as shown in Fig. 5.

\section{Multiscale friction model}

The friction framework developed by Hol [9] includes boundary and mixed lubrication regimes. However, because lubricants are not used in hot stamping, only the boundary lubrication part is extended to include temperature and coating effects [33]. The boundary lubrication framework can model different surface deformation phenomena that modify the workpiece 
surface. The multiscale friction framework comprises models describing the deformation of surface asperities due to normal loading, sliding of tool asperities on the sheet surface, and deformation of the substrate bulk material. The boundary lubrication friction regime is modeled in three steps, as shown in Fig. 6.

In the first step, the input parameters, such as the process parameters, sheet and tool surface topographies, and the material constitutive parameters, are processed.

In the second step, the deformation of surface asperities due to normal loading, bulk deformation, and sliding was calculated. Normal loading flattens the sheet metal asperities, and the real contact area evolves. The normal loading model proposed by Shisode et al. [24] that could model hot stamping was incorporated into the multiscale model. In their model, a soft rough coated surface was flattened by a hard smooth tool. To account for the increase in the contact real area due to the deformation in the bulk of the sheet, the Westeneng model [10] was implemented. Sliding causes an additional tangential load, resulting in an increase in the real contact area (junction growth); this phenomenon is accounted by Tabor's model [11].

In the third step, contact patches are defined [13], and shear stresses and COFs are calculated for each contact patch [12]. A phenomenological shear strength model in which a temperature term was added was implemented [34]. The overall COF was calculated by considering the COF for each contact patch.

The effect of temperature is included in the three steps of the multiscale framework. In the first step (input), the material constitutive properties are described by the Abspoel van Liempt model, which describes the temperature-dependent behavior of materials. In the second step, the amount of flattening and rise of asperities due to normal loading is calculated by solving the energy, momentum, and volume equations, which depend on the strength of the material and are thus temperature-dependent. In addition, the increase in the real contact area due to the combined bulk deformation and normal loading is modeled based on Westeneng's model [10]. In this model, the effective hardness and shear strength of the substrate material are governed by the temperature-dependent material model. In the third step, the temperature effect is included in the shear strength model.

\subsection{Input}

Temperature, contact pressure, and bulk strain are necessary input parameters for the calculations because they affect the asperity deformation. To calibrate the model, HFTs were used.

\subsubsection{Topography of sheet material and tool}

Sheet and tool topographies perform important roles in friction. Sheet metals generally have higher roughness than the tool surface. In sheet metal forming, the contact pressure leads to microscopic contact areas, adding up to the so-called real contact area, which is considerably smaller than the nominal contact area. The workpiece topography determines the size of these islands (contact patches) and the gap between the tool surface and mean surface of the workpiece. In the relative sliding of surfaces, tool asperities plow through the sheet surface on the contact patch islands, thereby generating a friction force.

To determine the tool and sheet topographies, confocal measurements are performed, as shown in Fig. 7. The sheet topography is measured on the strips

\begin{tabular}{|c|c|c|}
\hline Input & Asperity deformation & Shear stresses \& COF \\
\hline $\begin{array}{l}\text { 1. Process parameters } \\
\text { 2. Sheet \& tool surface } \\
\text { 3. Material Constitutive properties } \\
\text { Abspoel et al. [1] }\end{array}$ & $\begin{array}{l}\text { 1. Normal loading } \\
\text { Westeneng [10] } \\
\text { Shisode et al. [24] } \\
\text { 2. Bulk deformation } \\
\text { Westeneng [10] } \\
\text { 3. Sliding } \\
\text { Tabor [11] }\end{array}$ & $\begin{array}{l}\text { 1. Shear strength } \\
\text { Wang et al. [34] } \\
\text { 2. Single asperity model } \\
\text { Challen and Oxley [12] } \\
\text { 3. Multi asperity model } \\
\text { Ma et al. [13] }\end{array}$ \\
\hline
\end{tabular}

Fig. 6 Framework of multiscale friction model. 
(a)

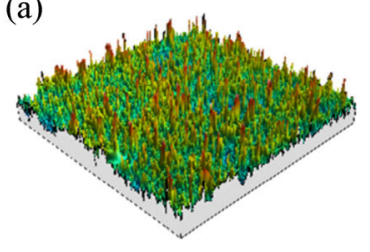

(b)

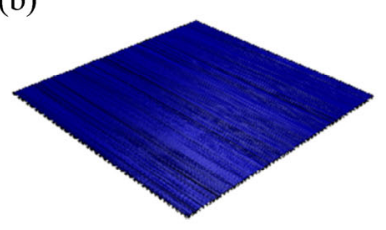

(c)

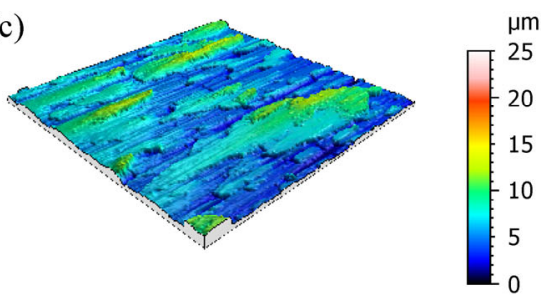

Fig. 7 Confocal measurements $(1 \mathrm{~mm} \times 1 \mathrm{~mm})$ : (a) sheet topography after heat treatment, (b) texture of clean tool, and (c) worn topography measurement tool at $650{ }^{\circ} \mathrm{C}$ after 10 strip draw tests.

after they have cooled to room temperature. The topography at the test temperatures is presumed to differ insignificantly from the topography after cooling to room temperature. Thus, the structure and topography of the coating are defined by the furnace treatment. Ghiotti et al. [16] and Borsetto et al. [35] investigated the effect of cooling rate on the structure and chemical composition after a thermal cycle; significant differences in the coating structure due to different cooling rates were not observed. In all strips, the variation in surface topography in one test series was relatively small; accordingly, one representative sheet topography was used for all normal loading and HFT model calculations.

For both sheet and tool surfaces, the size of the representative area used in the calculations was $1 \mathrm{~mm} \times 1 \mathrm{~mm}$. The sheet surface was relatively homogeneous and well represented by a size of $1 \mathrm{~mm} \times 1 \mathrm{~mm}$.

The tool topography was measured before the first strip draw test and after the $10^{\text {th }}$ test. As shown in Figs. 7(b) and 7(c), the tool surface changes because of tool wear. The tool wear was inhomogeneous, especially at higher temperatures. Therefore, for each test temperature, three confocal measurements were performed at different positions on the tool area.

\subsubsection{Material properties}

The material behaviors of the coating and substrate are described in the model. The Abspoel van Liempt [1] material model for the hardening behavior of a substrate (PHS) was implemented. The model decomposes the flow stress into three components:
(1) yield stress, (2) thermally activated stress, and (3) strain rate-dependent work-hardening component. The flow stress equation is [1]

$\sigma=\sigma_{0}+\left[\frac{U^{\prime}(T)}{\Omega(\dot{\varepsilon})}\right] \cdot\left\{1-\mathrm{e}^{-\left[\frac{\Omega(\dot{\varepsilon}, T)}{2}\right] \cdot \varepsilon}\right\}+\sigma_{0}^{*} \cdot\left[1+\frac{k_{\mathrm{B}} \cdot T}{\Delta G_{0}} \cdot \ln \left(\frac{\dot{\varepsilon}}{\dot{\varepsilon}_{0}}\right)\right]$

where $\sigma$ is the flow stress $(\mathrm{MPa}) ; \sigma_{0}$ is the thermal limit of yield stress (MPa); $\sigma_{0}^{*}$ is the dynamic stress at zero thermal activation (MPa); $U^{\prime}$ is the normalized hardening parameter $\left(\mathrm{mm}^{-1}\right) ; \Omega$ is the parameter describing annihilation and remobilization of dislocations; $\varepsilon$ is the plastic strain; $k_{\mathrm{B}}$ is the Boltzmann constant $(\mathrm{eV} / \mathrm{K}) ; T$ is the absolute temperature $(\mathrm{K})$; $\Delta G_{0}$ is the maximum activation energy $(\mathrm{eV}) ; \dot{\varepsilon}$ is the strain rate $(1 / \mathrm{s})$; and $\dot{\varepsilon}_{0}$ is the limit strain rate for thermally activated movement $(1 / \mathrm{s})$.

Table 1 lists the model parameter values used in the calculations [1]. The resulting curves are shown in Fig. 8(a).

The coating consisted of different intermetallics and voids. The number of voids was estimated from the coating cross-sections. Windmann et al. [36] determined the hardness values of several $\mathrm{Al}_{x} \mathrm{Fe}_{y}$ intermetallics at different temperatures. A linear fit between hardness and temperature was obtained for various intermetallics (Fig. 8(b)). The percentages of AlFe and $\mathrm{Al}_{5} \mathrm{Fe}_{2}$ were determined by scanning electron microscopy/energy dispersive $\mathrm{X}$-ray line measurements of the cross-section. The number of voids was estimated from the coating cross-sections. A mixture rule is implemented to approximate the hardness of coating

Table 1 Substrate material parameters.

\begin{tabular}{cccccccc}
\hline & $\sigma_{0}$ & $U^{\prime}$ & $\Omega$ & $k_{\mathrm{B}}$ & $\Delta G_{0}$ & $\sigma_{0}^{*}$ & $\dot{\varepsilon}_{0}$ \\
\hline PHS & 44 & $-10 T+13,500$ & $-1.73 \ln (\dot{\varepsilon})+18$ & $8.617 \times 10^{-5}$ & 1.8 & 188 & $10^{6}$ \\
\hline
\end{tabular}



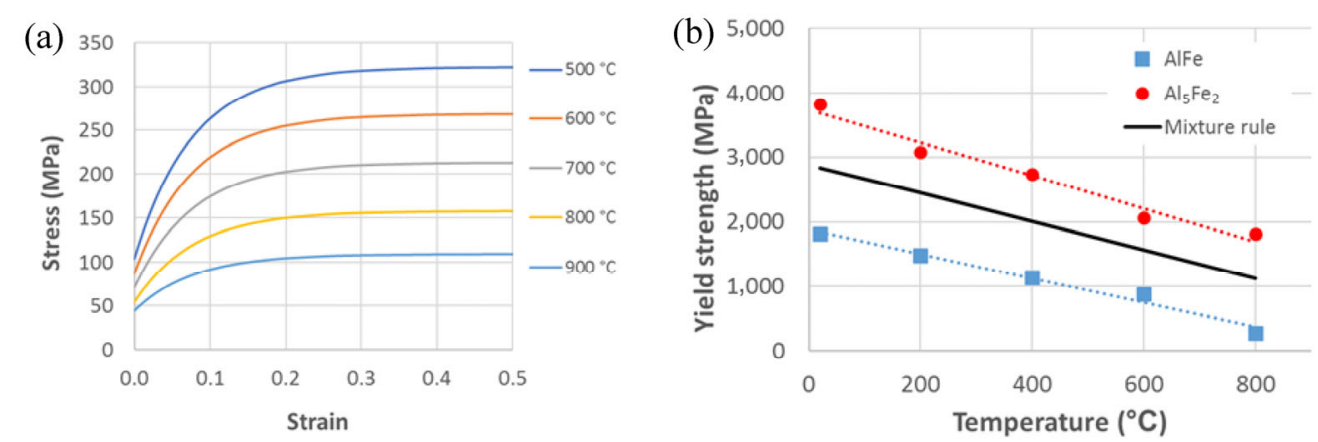

Fig. 8 (a) Stress-strain curves for substrate material model at different temperatures $(\dot{\varepsilon}=0.01)$ and (b) yield strength versus coating temperature.

in which the voids have zero hardness:

$$
\begin{gathered}
H_{\mathrm{c}}=\% \mathrm{AlFe} \cdot H_{\mathrm{AlFe}}+\% \mathrm{Al}_{5} \mathrm{Fe}_{2} \cdot H_{\mathrm{Al}_{5} \mathrm{Fe}_{2}} \\
H_{\mathrm{AlFe}}=-5.28 T+6,714 \\
H_{\mathrm{Al}_{5} \mathrm{Fe}_{2}}=-7.14 T+12,401
\end{gathered}
$$

where $H_{c}$ is the hardness of coating $(\mathrm{MPa}) ; H_{\mathrm{AlFe}}$ is the hardness of intermetallic $\mathrm{FeAl}(\mathrm{MPa}) ; \mathrm{H}_{\mathrm{Al}_{5} \mathrm{Fe}_{2}}$ is the hardness of intermetallic $\mathrm{Fe}_{2} \mathrm{Al}_{5}(\mathrm{MPa}) ; \% \mathrm{AlFe}$ is the percentage of intermetallic $\mathrm{FeAl}(1 / 100 \%)$; and $\% \mathrm{Al}_{5} \mathrm{Fe}_{2}$ is the percentage of intermetallic $\mathrm{Fe}_{2} \mathrm{Al}_{5}$ $(1 / 100 \%)$.

The hardening behavior of the coating material is unknown. Therefore, the coating material is modeled as ideally plastic with a yield stress of $1 / 2.8$ times the hardness [37]. The coating material parameters are listed in Table 2.

Table 2 Coating material parameters.

\begin{tabular}{cccc}
\hline & \%voids & \%AlFe & $\% \mathrm{Al}_{5} \mathrm{Fe}_{2}$ \\
\hline PHS & 5 & 36 & 59 \\
\hline
\end{tabular}

\subsection{Asperity deformation}

Asperity deformation is caused by normal loading (Section 3.2.1), sliding (Section 3.2.2), and bulk deformation (Section 3.2.3).

\subsubsection{Normal loading}

The tool is modeled as rigid and perfectly flat when it flattens the asperities of a soft rough workpiece material. The workpiece asperities (substrate and coating) were modeled as bars. The bars in contact with the tool are indented, and the non-contacting bars rise, as shown in Fig. 9. The amount of flattening and rise of asperities due to normal loading (thus, the real contact area) can be calculated by solving the energy, momentum, and volume conservation equations [24]. The force balance, volume, and energy conservation equations are written in a stochastic form using the normalized height distributions for the coating and substrate [24]. The indentation, rise of bars, and fractional real contact area are calculated by solving the equations for a certain normal pressure using the Newton-Raphson method. More detailed information on the model can be found in Refs. $[9,33]$.

Determining the substrate topography after heating is not possible because of the diffusion process in the furnace. Therefore, the same surface topography as the coating was used for the substrate, effectively assuming a constant coating thickness.

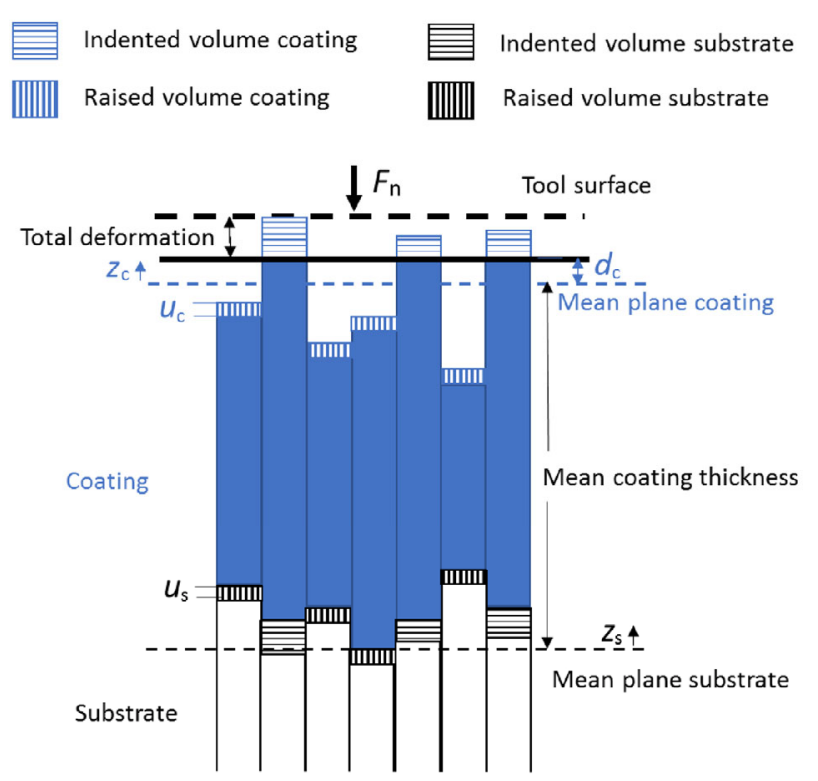

Fig. 9 Schematic of normal loading model. 
The real contact area due to the normal loading calculated by the model is within the range of real contact areas determined from normal loading experiments at average contact pressures of 10 and $20 \mathrm{MPa}$ (Fig. 10). Compared with the flattening tests, the model predicts lower real contact areas at a low contact pressure (5 $\mathrm{MPa}$ ) and high temperature values (700 and $800{ }^{\circ} \mathrm{C}$ ). This may be the result of the inaccuracy in determining the lower and upper bounds from the height distribution curves, leading to calculation errors in the experimental real contact area at low pressure values.

The smooth hard tool and relatively soft rough sheet coating are initially in contact. However, worn materials, consisting of oxides, coating intermetallics, and tool debris, accumulate on the tool. Tool wear has two implications for the main assumptions of the normal loading model. First, the disparity in roughness between the tool and sheet is considerably reduced, and the assumption that the tool is flat at the mesoscale level may not hold. This can be rectified by considering the tool roughness in the normal contact model; an overview of such models is given by Ref. [38]. Second, the new hardness (including wear) of the tool is unknown. To investigate this, normal loading tests were performed at $700{ }^{\circ} \mathrm{C}$ using tools with adhesive (i.e., severe) wear. The results revealed that the tool wear the did not significantly deform after loading; therefore, the tool wear did not affect the prediction of the real contact area in normal loading models. The material that has adhered on the tool are possibly harder than the coating, although some fractures are observed at the sharp edges. Overall, these factors may result in a less accurate prediction of the actual contact area. Despite these problems, the normal loading model accurately predicts the real contact area.

\subsubsection{Sliding}

The increase in the real contact area during sliding is calculated by considering two mechanisms [9]. In the normal loading model, a flat tool is assumed, and a force equilibrium between the applied load and calculated real contact area exists. However, during sliding, the rough tool asperities plow through the softer workpiece asperities. This means that only the front area (half) of the penetrating tool asperities are in contact. Accordingly, the real contact area is multiplied by two to satisfy the force equilibrium. The second mechanism is the so-called junction growth phenomenon [11]. Tabor [11] stated that the tangential load during sliding has to result in an increase in the real contact area to maintain a constant von Mises stress at the contact points that have yielded. To consider this mechanism, the Tabor equation is incorporated into the model:

$$
v=\sqrt{1+k \mu^{2}}
$$

where $v$ is the increase in fractional real contact area and $k$ is the constant shear factor.

The value of $k$ can either be determined experimentally [27-29] or used as a fitting parameter [9]. The $k$ value was intended as a fitting parameter to match the calculated real contact areas to the measured real contact areas from the HFT experiments. However, the experimentally determined real contact areas were not correct because of the history effect on the experiment. The measured real contact area is the result of more contact situations than the contact condition in
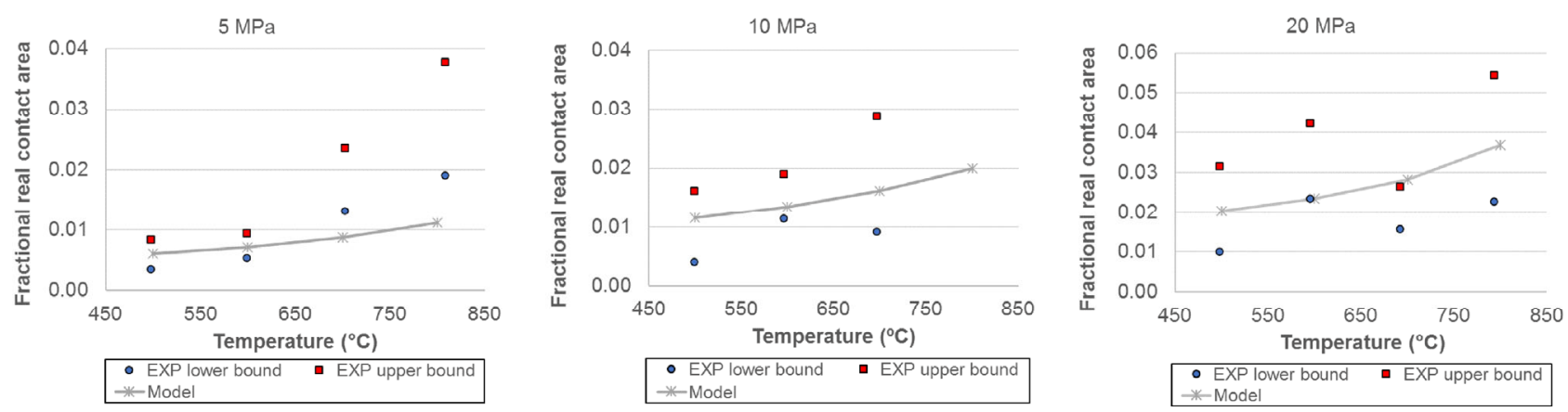

Fig. 10 Fractional real contact area versus temperature determined from experiments (dots) and predicted by model (gray line) at 5, 10 (left), and $20 \mathrm{MPa}$ (right); red squares and blue circles represent upper and lower bounds of real contact area, respectively. 
the model where only one tool area (i.e., $1 \mathrm{~mm} \times 1 \mathrm{~mm}$ ) is considered. Because fitting the $k$ value into the measured real contact areas was impossible, it was fitted into the COF values. Realistic COF values were obtained as $k$ values of 5.5 and 2 were used for the clean and worn tools, respectively (Fig. 11). These values were used for the calculations.

The theory behind the model may not be fully applicable to the situation under consideration. In the model, only junction growth results in the increase in the real contact area because of the additional tangential load. However, in hot stamping, the increase in real contact areas is not only caused by plastic deformation but also coating fracture, as indicated by the presence of a considerable amount of tool pollution.

\subsubsection{Bulk deformation}

The bulk straining of the underlying material reduces hardness [21, 22, 39]. Westeneng [10] formulated a model that included this effect. The change in the fractional real contact area is calculated by solving the equations for the rise and indentation of asperities, whereas the strain is incrementally increased. However, data are not currently available to validate the straining step at high temperature values. In this study, the model parameters from Ref. [9] were adopted.

\subsection{Shear stresses \& COF}

After the real contact area has been determined, the friction calculation is performed in three steps. First, the contact patches are determined using binary image processing techniques [13], as shown in Fig. 12(a). Elliptical paraboloids are fitted through the height

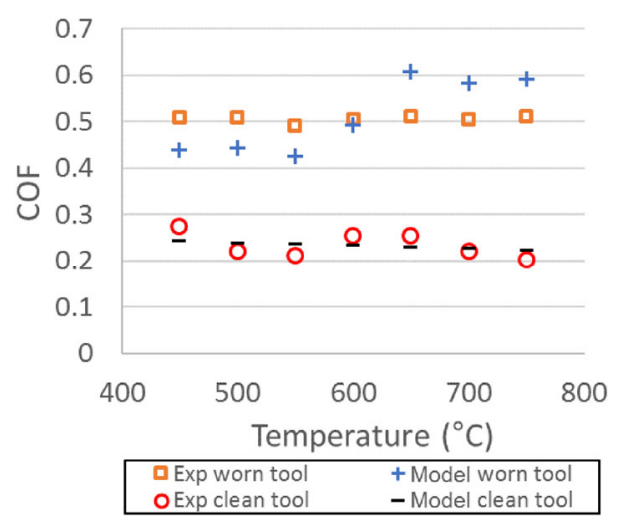

Fig. 11 COF versus temperature predicted by model and measured from experiments for clean and worn tools.
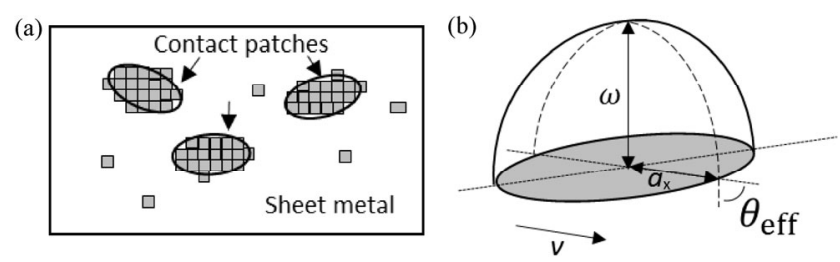

Fig. 12 (a) Schematic of contact patches and (b) geometric characteristics of elliptical paraboloid fitted on asperities.

data to determine the attack angle [13], as shown in Fig. 12(b). With the attack angle and shear factor, the friction force for each contact patch can be calculated using the Challen and Oxley model [12]. In the final step, the overall COF, including the contributions from all contact patches, was calculated.

\subsubsection{Interfacial shear strength}

In the model of Challen and Oxley [12], the COF is determined by the attack angle and shear factor. The shear factor is defined as the shear strength of the interfacial boundary layer divided by the shear strength of the plastically deformed bulk material.

Timsit and Pelow [40] measured the interfacial shear strengths of stearic acid on aluminum. Westeneng [10] fitted the reported experimental values using power laws. An extra temperature variable was introduced to the model of Timsit and Pelow. Furthermore, the shear strength of the interfacial boundary layer of the worn and clean tools differs because the material that has adhered to the tool surface alters the material types that are in contact. The boundary layer shear strength is formulated as follows:

$$
\begin{gathered}
\tau_{\mathrm{b}}=c H_{\text {eff }}{ }^{n} \mathrm{e}^{-m T} \\
H_{\text {eff }}=\frac{p_{\text {nom }}}{\alpha}
\end{gathered}
$$

where $\tau_{\mathrm{b}}$ is the boundary layer shear strength (Pa); $p_{\text {nom }}$ is the nominal contact pressure $(\mathrm{Pa}) ; H_{\text {eff }}$ is the effective hardness (Pa); $c, n, m$ are constants; and $\alpha$ is the fractional real contact area.

The constants $c, m$, and $n$ are calibrated to obtain a COF similar to those of the strip-draw tests for the combination of clean tool and Al-Si coating as well as the combination of tool wear and Al-Si coating. The clean tool is not stable because the tool wear starts immediately. The first point of each measurement is 
regarded as the experimental value of the COF of the clean tool at a given temperature. After a certain number of strokes in the experiments, the COF virtually becomes independent of temperature. In contrast, tool wear is temperature-dependent and modifies the tool topography. For each temperature value, confocal measurements of the tool were performed after 10 slides. In the case of worn tools, the interfacial shear strength parameters were calibrated for $k=2$. For each temperature value, calculations were performed with the three tool topographies; the average value was thereafter calculated. Only a slight temperature dependency of the interfacial shear strength is considered $\left(m=10^{-5}\right)$; otherwise, an unrealistic increase in the COF can occur for the top-hat stamping case in which the tool wear is measured at only one temperature value. The values listed in Table 3 provide the best agreement with experimental data, and Fig. 11 shows the model results with these values.

The calculated interfacial boundary layer shear strength for the cases of clean and worn tools is shown in Fig. 13. At various temperatures, the boundary layer shear strength of the latter was higher than that of the former. In the case of the worn tool, the higher shear strength could be due to the fusion of the coating material that had adhered on the tool surface and sheet metal coating. The boundary layer shear strength

Table 3 Parameters of interfacial shear strength power law.

\begin{tabular}{cccc}
\hline & $c$ & $n$ & $m$ \\
\hline Timsit and Pelow & 3.94 & 0.81 & - \\
Clean tool & 9 & 0.81 & $2 \times 10^{-3}$ \\
Worn tool & 4.8 & 0.81 & $1 \times 10^{-5}$ \\
\hline
\end{tabular}

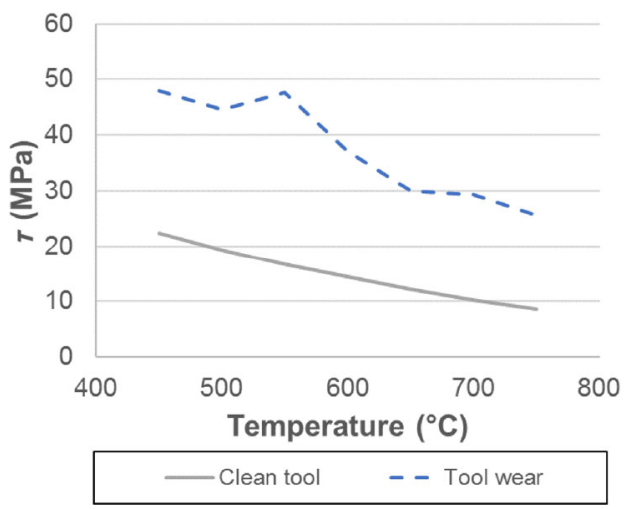

Fig. 13 Interfacial boundary shear strength for clean and worn tools. is essentially the shear strength of the coating. Tool wear is temperature-dependent, and for each temperature value, calculations are performed with the corresponding tool topography measurement. Because of this varying tool wear topography, the fractional real contact area does not have a "smooth" relationship with temperature; this explains the lesser smoothness of its line shown in Fig. 13 than that of the clean tool.

\subsubsection{Single asperity}

The COF for each contact patch was calculated using the Challen and Oxley model [12]. The attack angle is calculated for a wedge-shaped asperity [12], as shown in Fig. 12(b). Based on this angle, the active mode (cutting, plowing, and wear) is determined using the wear-mode diagram [41] shown in Fig. 14. For each regime, an equation for the COF as a function of the attack angle and shear factor is given by the Challen and Oxley model [12].

The COF in the cutting regime is as follows [12]:

$$
\mu_{c u}=\tan \left[\theta-\frac{1}{4} \pi+\frac{1}{2} \arccos \left(f_{c}\right)\right]
$$

The COF in the plowing regime is given by the following [12]:

$$
\begin{gathered}
\mu_{\mathrm{pl}}=\frac{A_{1} \sin \theta+\cos \left[\arccos \left(f_{\mathrm{c}}-\theta\right)\right]}{A_{1} \sin \theta+\sin \left[\arccos \left(f_{\mathrm{c}}-\theta\right)\right]} \\
A_{1}=1+\frac{1}{2}+\arccos \left(f_{\mathrm{c}}\right)-2 \theta-2 \arcsin \left[\frac{\sin (\theta)}{\left(1-f_{\mathrm{c}}\right)^{1 / 2}}\right]
\end{gathered}
$$

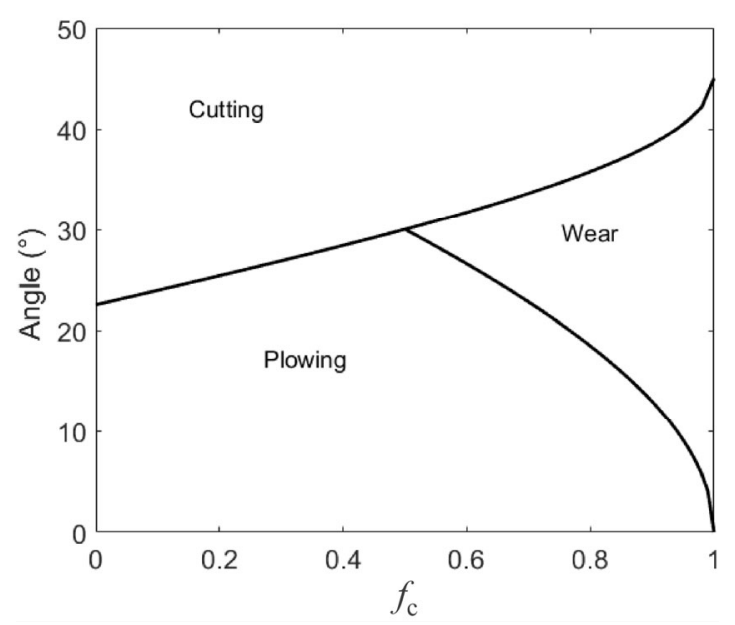

Fig. 14 Wear mode diagram. 
The COF in the wear regime is [12]

$$
\begin{aligned}
& \mu_{\text {we }}=\frac{\left[1-2 \sin A_{2}+\left(1-f_{\mathrm{c}}^{2}\right)^{\frac{1}{2}}\right] \sin \theta+f_{\mathrm{c}} \cos \theta}{\left[1-2 \sin A_{2}+\left(1-f_{\mathrm{c}}^{2}\right)^{\frac{1}{2}}\right] \cos \theta-f_{\mathrm{c}} \sin \theta} \\
& A_{2}=1-\frac{1}{4} \pi-\frac{1}{2} \arccos f_{\mathrm{c}}+\arcsin \left[\frac{\sin \theta}{\left(1-f_{\mathrm{c}}\right)^{\frac{1}{2}}}\right]
\end{aligned}
$$

where $\theta$ is the attack angle and $f_{\mathrm{c}}$ is the shear factor.

The shear factor is defined as

$$
f_{\mathrm{c}}=\frac{\tau_{\mathrm{b}}}{k_{\mathrm{s}}}
$$

Where $\tau_{\mathrm{b}}$ is the shear strength of interfacial boundary layer $(\mathrm{MPa})$ and $k_{\mathrm{s}}$ is the shear strength of plastically deforming material (MPa).

The shear strength of the interfacial boundary layer is described by a power law. The shear strength of the plastically deforming material can be expressed as

$$
k_{\mathrm{s}}=\frac{H}{B \sqrt{3}}
$$

where $H$ is the hardness (MPa) and $B$ is the hardness factor.

Factor $B$ was experimentally determined by Tabor [11] as approximately 2.8 .

The effects of the shear factor and attack angle on the COF are shown in Figs. 15(a) and 15(b), respectively. A higher shear factor in the plowing and wear regime results in a higher COF, whereas in the cutting regime, it results in a lower COF. The clean tool and worn tool cases result in $f_{\mathrm{c}}$ values in ranges $0.14-0.23$ and $0.53-0.61$, respectively. A larger attack angle generally

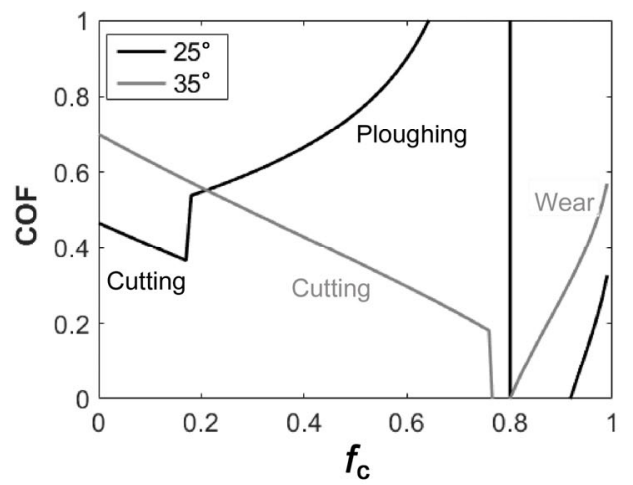

Fig. 15 (a) COF versus shear factor for attack angles of $25^{\circ}$ and $35^{\circ}$; results in a higher COF, except when a step is applied to another regime (Fig. 15(b)).

\subsubsection{Multiple asperity model}

The model developed by Ma et al. [13] was used to determine the attack angles. The sheet and tool surfaces are projected onto each other. The sheet surface was adapted for the amounts of flattening and rise of asperities obtained from the flattening models. A binary image processing technique was employed to identify the contact patches, and an elliptical paraboloid is fitted through a contact patch [13]. The effective attack angle between the elliptic paraboloid and the counter surface is calculated [9], see Fig. 12(b):

$$
\theta_{\text {eff }}=\arctan \left(\frac{2 \omega}{a_{x}}\right)
$$

where $\theta_{\text {eff }}$ is the effective attack angle; and $\frac{2 \omega}{a_{x}}$ is the tangent of elliptical paraboloid.

The effective attack angle is required to calculate the friction force on the contact patch. This friction force was calculated using the Challen and Oxley model [12]. However, this model is a two-dimensional (2D) plane strain expression. Hence, a shape factor was introduced by Hokkirigawa and Kato [42] to transform the effective attack angle from a 3D to a 2D case. A shape factor of 0.8 , which they found for brass, carbon steels, and austenitic stainless steels, was applied to the friction model.

\subsubsection{COF}

The overall COF is calculated by dividing the summation of all individual friction forces on the

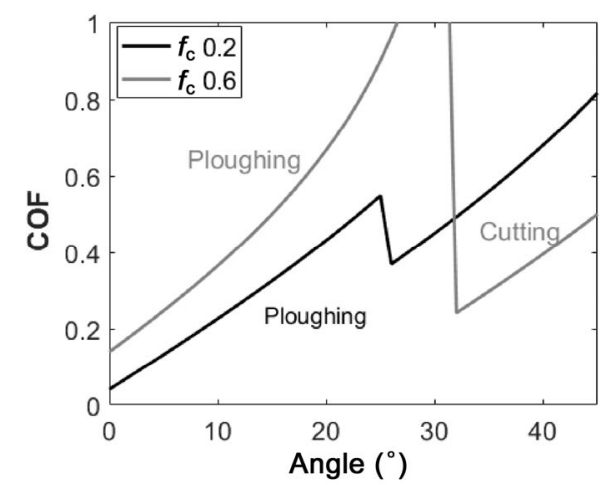

; (b) COF versus attack angle for shear factors of 0.2 and 0.6 . 
contact patches by the total normal load, which is also the summation of the loads on all contact patches [9]:

$$
\mu=\frac{F_{w}}{F_{N}}=\frac{\sum_{i=1}^{j} \mu_{i}\left(\theta_{i}\right) A_{i} H}{\sum_{i=1}^{j} A_{i} H}
$$

Where $j$ is the number of contact patches; $\mu_{i}$ is the COF of contact patch $i ; \theta_{i}$ is the attack angle of contact patch $i ; A_{i}$ is the area of contact patch $i\left(\mathrm{~mm}^{2}\right)$; and $H$ is the hardness (MPa).

The tool (surface) topography is important for determining the contact angles, which are relevant to the calculation of friction; thus, it performs an important function. In hot stamping, severe tool wear, which can quickly occur, modifies the tool surface texture. Confocal measurements were performed on a clean tool surface then on the resulting tool surface after 10 sliding repetitions, each $220 \mathrm{~mm}$. Calculations based on the clean tool correspond to the start value of the friction curve versus displacement; here, the coating is in contact with the clean tool. The predicted COF is 0.22 , which is equal to the experimental value. Calculations based on the worn tool result in a COF of 0.52 , which approximates the final value of 0.50 , as shown in Fig. 16. The COF value increases because of the larger attack angles and higher interfacial shear strength factor ( 0.6 for the worn tool versus 0.2 for the clean tool). For the clean tool, the percentage of asperities in the cutting regime (in the model, i.e., $~ 5 \%$ ) was smaller than that for the worn tool ( $8 \%-29 \%)$.

\section{Application to forming processes}

The previous sections describe a friction model for hot stamping. This section presents the implementation of this friction model in the FE simulation of the fabrication of a top-hat product.

\subsection{FE simulation input}

COFs were calculated for the actual tool and sheet surface topography using the calibrated friction model described above. The COFs are the basis of the friction files that are used in the FE simulation. Separate friction files were constructed for the punch-workpiece and die-workpiece contacts, accounting for different textures of the die and punch.

The experiments show that severe wear accumulates on the die radius (Fig. 5); accordingly, friction files are created for three situations: (a) clean tool (before testing), (b) moderate wear (after five strokes), and (c) severe wear (after 50 strokes). The punch shows a negligible increase in wear; therefore, only one friction file is constructed for the punch. Confocal measurements of the die (with a $45^{\circ}$ radius), punch (with $45^{\circ}$ replica radius), and sheet surface were used as inputs for the multiscale friction model. The coating properties are the same as those described in Section 3.1.2. The substrate material used in these experiments differs from that used in the strip-draw experiments. The model parameters are listed in Table 4-7. The hardening curves were constructed using the Abspoel van Liempt material model [1]; a Vegter-yield surface was used. An elasticity modulus of $105 \mathrm{MPa}$ was employed.

The friction model provides the real contact area and $\mathrm{COF}$ as a function of the process parameters, namely the contact pressure, strain, and temperature. These values were obtained from the FE simulation

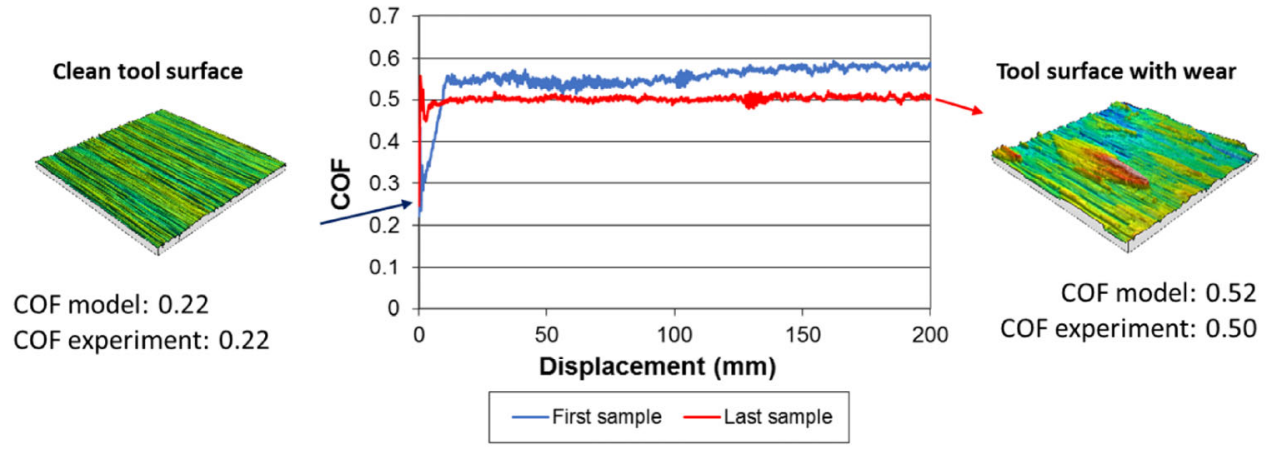

Fig. $16 \mathrm{COF}$ versus displacement from experiment at $700{ }^{\circ} \mathrm{C}$ : first sample calculation with clean tool and last sample calculation with worn tool. 
Table 4 Heat transfer coefficient (HTC): heat transfer to surrounding.

\begin{tabular}{ccc}
\hline & $20^{\circ} \mathrm{C}$ & $950{ }^{\circ} \mathrm{C}$ \\
\hline $\operatorname{HTC}\left(\mathrm{mW} /\left(\mathrm{mm}^{2} \cdot \mathrm{K}\right)\right)$ & 0.020 & 0.145 \\
\hline
\end{tabular}

of the forming process at the location of each element and each simulation increment. This means that the COF for each element in contact can vary with location (i.e., on the part) and time (deformation increment). The COF values predicted by the model are in the expected range (i.e., 0.28-0.68), as shown in Fig. 17. The lowest COF values were obtained for the clean die, whereas the highest COF values were obtained for the case simulating severe wear. The punch is rougher than the clean die, thus resulting in a higher friction compared with that in the die. Furthermore, the difference between moderate wear and severe wear on the die was relatively small. A low temperature dependency was observed because of the calibration of the interfacial shear strength model from the HFT experiments (Section 3.3.1). The increase in pressure, however, resulted in a decrease in the COF; this was also noted in some reports in the literature (Section 3.2.1).

Using the friction values in Fig. 17, the top-hat fabrication is simulated for the first product (friction files: clean die and punch), $5^{\text {th }}$ product (friction files: moderate wear and punch), and $50^{\text {th }}$ product (friction files: severe die wear and punch). The distribution of COFs throughout the part at a drawing depth of $50 \mathrm{~mm}$ is shown in Fig. 18. The results show that the tool wear has a considerable effect on the COF, and the use of clean tools leads to relatively low COFs. The values vary in the range of $0.30-0.60,0.41-0.60$, and $0.41-0.68$ for the clean tool, die with moderate wear, and die with severe wear, respectively.

Table 5 HTC: heat transfer to tool with pressure dependency scaling factor.

\begin{tabular}{ccccccc}
\hline & & $0 \mathrm{MPa}$ & $1 \mathrm{MPa}$ & $2 \mathrm{MPa}$ & $3 \mathrm{MPa}$ & $20 \mathrm{MPa}$ \\
\hline $\mathrm{HTC}\left(\mathrm{mW} /\left(\mathrm{mm}^{2} \cdot \mathrm{K}\right)\right)$ & 3.5 & 0.3 & 0.7 & 0.8 & 0.9 & 1 \\
\hline
\end{tabular}

Table 6 Abspoel van Liempt flow stress parameters of substrate material.

\begin{tabular}{|c|c|c|c|c|c|c|c|}
\hline & $\sigma_{0}$ & $U^{\prime}$ & $\Omega$ & $k_{b}$ & $\Delta G_{0}$ & $\sigma_{0}^{*}$ & $\dot{\varepsilon}_{0}$ \\
\hline PHS2 & 30 & $\begin{array}{c}\operatorname{Max}\left(0.0102 T^{2}-29 T+\right. \\
21,500+215 \ln (\dot{\varepsilon}) ; 500)\end{array}$ & $-0.326 \ln (\dot{\varepsilon})+0.0103 T+3.25$ & $8.617 \times 10^{-5}$ & 3.5 & 210 & 1012 \\
\hline
\end{tabular}

Table 7 r values (Lankford coefficients) at various temperatures.

\begin{tabular}{ccccc}
\hline Temperature & r0 & r45 & r90 & 0.78 \\
$600^{\circ} \mathrm{C}$ & 0.65 & 0.58 & 0.81 & 0.88 \\
$700^{\circ} \mathrm{C}$ & 0.72 & 0.80 & \\
\hline
\end{tabular}

(a)

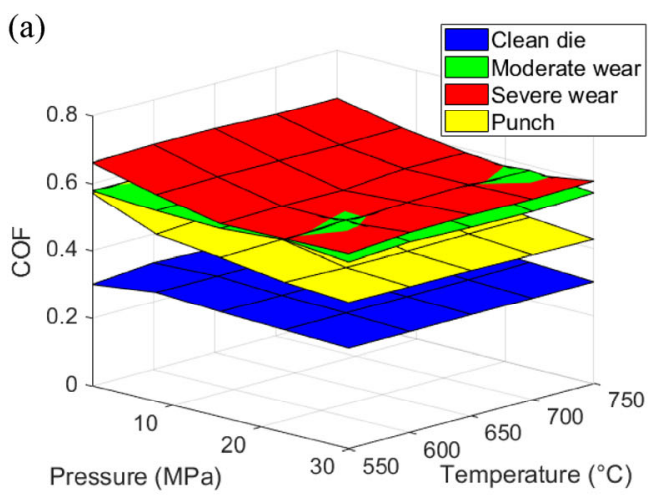

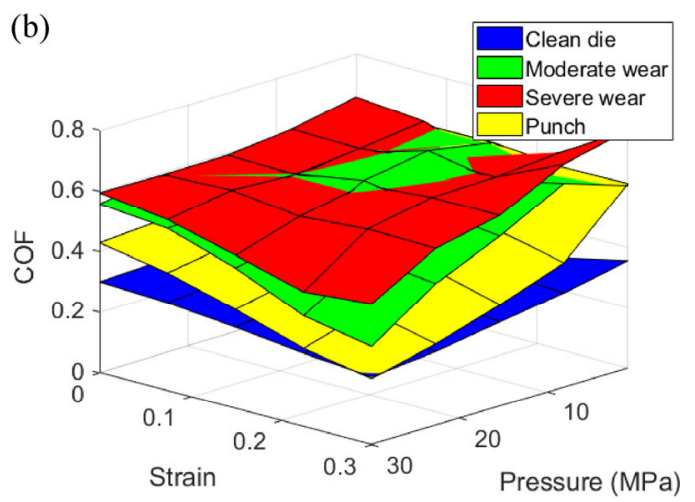

Fig. 17 Friction metamodel for clean die, punch, die with moderate wear, and die with severe wear: (a) cross-section at constant strain of 0 and (b) cross-section at constant temperature of $700{ }^{\circ} \mathrm{C}$. 
(a)

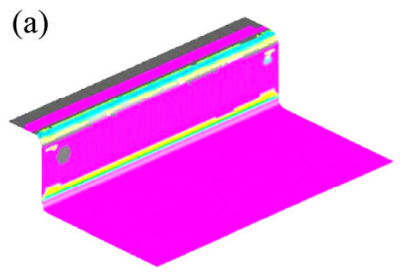

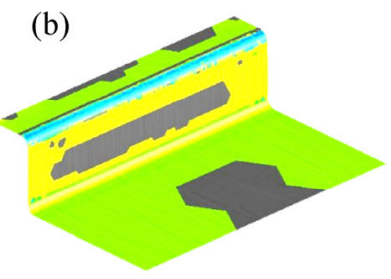
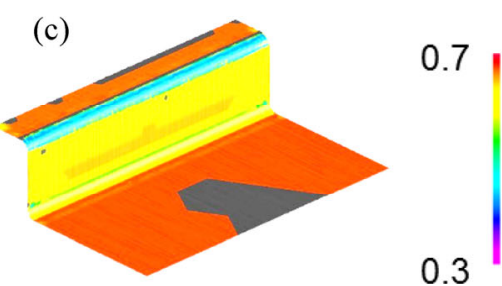

Fig. $18 \mathrm{COF}$ after $50 \mathrm{~mm}$ of drawing for (a) clean die ( $1^{\text {st }}$ product), (b) die with moderate wear ( $5^{\text {th }}$ product), and (c) die with severe wear $\left(50^{\text {th }}\right.$ product $)$.

The FE simulation results of the top-hat fabrication for product 1 (clean die), product 5 (die with moderate wear), and product 50 (die with severe wear) are shown in Fig. 19. In both simulation and experiment, the product exhibits low sensitivity to friction. Usually, in cold deep drawing, the top-hat product is sensitive to friction because of the blank holder force. In hot stamping, a blank holder force is not present because spacers are used; apparently, this reduces the sensitivity to friction. Different from the experiment, the model predicted less thinning and more draw-in. To some extent, the error is larger for the first product because a "clean tool" friction file is used, whereas wear on the tool has already started to accumulate in the first slide.

\section{Discussion}

In this work, the application of an existing multiscale model was extended to hot stamping by including temperature dependency and coating effects. The model is based on plastic deformation; however, hot stamping fracture and loose particles play a role as well, thus causing certain discrepancies.

Several model assumptions were not satisfied or

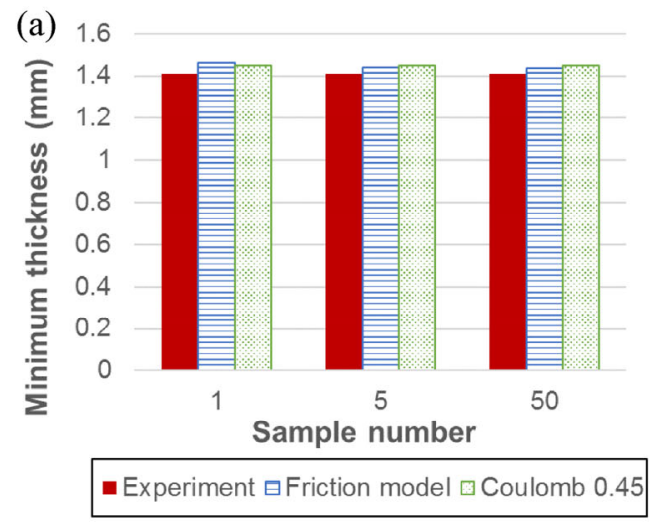

only partially satisfied. One assumption is that, a hard flat tool plows through a soft rough surface. At the start of the process, clean tools are used. However, in terms of tool wear, the roughness of the tool is not always lower than that of the sheet (workpiece). This results in a less accurate prediction of the real contact area in the normal loading step in which a perfectly flat tool is assumed. In addition, the hardness of the worn tool is unknown and may not exceed the sheet coating hardness. However, the tool wear is a combination of oxides, sheet coating intermetallics, and tool debris; moreover, normal loading tests using a worn tool reveal virtually no deformation of the wear on the tool. This indicates that the material that has adhered on the tool is harder than the coating on the sheet. The main deformation (fracture) occurred in the sheet coating. The mechanism of tool asperities (or tool wear) plowing through the sheet is observed over the entire temperature range. It can be concluded that the model is partially valid.

Determining the real contact areas in the experiments is difficult because of the non-flat tool, elasticity, and fracture of the asperities; consequently, an experimental range is indicated. The real contact areas that are calculated using the normal loading model are within

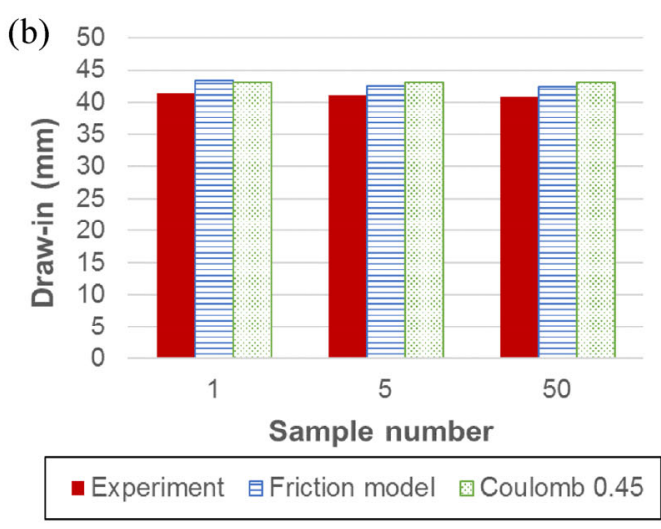

Fig. 19 Experiment and simulation results of (a) minimum thickness and (b) draw-in. 
this range. After sliding, the real contact areas can be fitted using the $k$ factor of Tabor's model.

The calibration of the interfacial shear strength values for a worn tool is difficult because the tool wear is extremely inhomogeneous, and inhomogeneity makes the calibration of the interfacial shear strength parameters considerably exigent. Only a slight temperature dependency of the interfacial shear strength is included (low $m$ value of $10^{-5}$ ); otherwise, an unrealistic increase in the COF values can occur in the demonstration case in which only the tool wear at one temperature value has been measured. A better alignment of the tools is expected to result in better homogeneity.

The top hat was found to be friction insensitive; therefore, the effect of wear on thickness or draw-in could not be observed. This is mainly because a blank holder force is not applied to top-hat stamping. Therefore, the sheet metal thickness and draw-in are mainly influenced by the accuracy of the material behavior description; the results indicate that these parameters are reasonably well predicted.

The measurements revealed that after a certain number of slides, the COF was temperatureindependent. This directly raises the question of whether it is advantageous to develop a temperaturedependent friction model. It may seem better to simply use a constant COF; however, to accurately predict friction, a satisfactory description of the tool texture is necessary. The evolution of tool topography is temperature-dependent [32]; hence, temperature effects should be included in the final model.

\section{Conclusions and recommendations}

The application of an existing multiscale model was extended to hot stamping. The material description and topography measurements of the sheet metal and tool are necessary inputs for calculating the real contact areas and COFs. The output is a database of COFs and real contact areas that is implemented in a full-scale FE model.

From the moment that wear starts to accumulate on the tool, a different contact situation occurs. The wear on the tool plows through the relatively soft sheet surface-A mechanism that is described in the extended multiscale friction model. The effect of tool wear on the COF is significant based on calculations using a clean tool topography (start of the HFT test) and worn tool topography (end of the HFT test). The calculated values satisfactorily represent the observed effect of the increase in the COF in the first sliding test. Furthermore, the demonstration case showed that tool wear in hot stamping could be extremely inhomogeneous on the tool surface. Therefore, the inclusion of a galling model to predict tool wear is highly recommended. Consequently, more accurate COFs are obtained without performing numerous measurements. Galling is currently one of the main problems in hot stamping; thus, the prediction of galling may also be used for process optimization and maintenance cost reduction.

The application of the calibrated friction model was demonstrated in the simulation of the fabrication of a hot-stamped part. The selected part was observed to be friction-insensitive. Hence, the validation of the multiscale friction model on another more frictionsensitive product is recommended. Finally, the calibrated friction model in this study may be employed to better comprehend the friction mechanism and the effect of different process parameters on hot stamping.

\section{Acknowledgements}

The authors would like to thank Richard Stegeman, Marco Appelman, Tu Phan, Gerben Botman, and Menno de Bruine for assistance with the measurements and Johan Hol (TriboForm Engineering BV) for the assistance with the import of the COFs in AutoForm.

Open Access This article is licensed under a Creative Commons Attribution 4.0 International License, which permits use, sharing, adaptation, distribution and reproduction in any medium or format, as long as you give appropriate credit to the original author(s) and the source, provide a link to the Creative Commons licence, and indicate if changes were made.

The images or other third party material in this article are included in the article's Creative Commons licence, unless indicated otherwise in a credit line to the material. If material is not included in the article's Creative Commons licence and your intended use is not permitted by statutory regulation or exceeds the 
permitted use, you will need to obtain permission directly from the copyright holder.

To view a copy of this licence, visit http://creativecommons.org/licenses/by/4.0/.

\section{References}

[1] Abspoel M, Neelis B, van Liempt P. Constitutive behavior under hot stamping conditions. J Mater Process Technol 228: 34-42 (2016)

[2] Karbasian H, Tekkaya A E. A review on hot stamping. J Mater Process Technol 210(15): 2103-2118 (2010)

[3] Li M, Chiang T, Tseng J, Tsai C. Hot stamping of door impact beam. Procedia Eng 81: 1786-1791 (2014)

[4] Cui J J, Sun G Y, Xu J R, Huang X D, Li G Y. A method to evaluate the formability of high-strength steel in hot stamping. Mater Des 77: 95-109 (2015)

[5] Mu Y H, Zhou J, Wang B Y, Wang Q L, Ghiotti A, Bruschi S. Numerical simulation of hot stamping by partition heating based on advanced constitutive modelling of $22 \mathrm{MnB} 5$ behaviour. Finite Elem Anal Des 147: 34-44 (2018)

[6] Stupkiewicz S, Mróz Z. A model of third body abrasive friction and wear in hot metal forming. Wear 231(1): 124-138 (1999)

[7] Wang L. Modelling of friction for high temperature extrusion of aluminium alloys. Ph.D. Thesis. Delft (the Netherlands): Delft University of Technology, 2012.

[8] Merklein M, Rosenschon M, Schwingenschlogl M. Characterization and Description of the Tribological Conditions Within Hot Stamping and Partial Hot Stamping of Quenchenable Ultra High Strength Steels. Düsseldorf (Germany): Verlag und Vertriebsgesellschaft mbH, 2018.

[9] Hol J. Multi-scale friction modeling for sheet metal forming. Ph.D. Thesis. Enschede (the Netherlands): University of Twente, 2013.

[10] Westeneng J. Modelling of contact and friction in deep drawing processes. Ph.D. Thesis. Enschede (the Netherlands): University of Twente, 2001.

[11] Tabor D. Junction growth in metallic friction: the role of combined stresses and surface contamination. Proc $R$ Soc London Series A 251: 378-393 (1959)

[12] Challen J M, Oxley P L B. An explanation of the different regimes of friction and wear using asperity deformation models. Wear 53(2): 229-243 (1979)

[13] Ma X, de Rooij M, Schipper D. A load dependent friction model for fully plastic contact conditions. Wear 269(11-12): 790-796 (2010)

[14] Vilaseca M, Pujante J, Casellas D, Dessain C, Blaise A,
Bachmann M, Alsmann M, Hamasaiid A, Grausem M, Eriksson K, et al. Wear Measurement Methodology and Test Facility to Increase the Effiicency of Hot Stamping for High Performance Component Production (TESTTOOL). Luxembourg (LU): Publications Office of the European Union, 2014.

[15] Hardell J, Prakash B, Steinhoff K. High temperature tribological studies on surface engineered tool steel and high strength boron steel. Steel Res Int 80(9): 665-670 (2009)

[16] Ghiotti A, Bruschi S, Borsetto F. Tribological characteristics of high strength steel sheets under hot stamping conditions. J Mater Process Technol 211(11): 1694-1700 (2011)

[17] Venema J, Matthews D T A, Hazrati J, Wörmann J, van den Boogaard A H. Friction and wear mechanisms during hot stamping of AlSi coated press hardening steel. Wear 380-381: 137-145 (2017)

[18] Greenwood J A, Williamson J B P. Contact of nominally flat surfaces. Proc R Soc London Series A 295: 300-319 (1966)

[19] Shisode M P, Hazrati J, Mishra T, de Rooij M B, van den Boogaard A H. Semi-analytical contact model to determine the flattening behavior of coated sheets under normal load. Tribol Int 146: 106182 (2020)

[20] Pullen J, Williamson J B P. On the plastic contact of rough surfaces. Proc R Soc London Series A 327: 159-173 (1972)

[21] Wilson W R D, Sheu S. Real area of contact and boundary friction in metal forming. Int $J$ Mech Sci 30(7):475-489 (1988)

[22] Sutcliffe M P F. Surface asperity deformation in metal forming processes. Int J Mech Sci 30(11): 847-868 (1988)

[23] Zhao Y W, Chang L. A model of asperity interactions in elastic-plastic contact of rough surfaces. $J$ Tribol 123(4): 857-864 (2001)

[24] Shisode M, Hazrati J, Mishra T, de Rooij M, van den Boogaard T. Multi-scale contact modeling of coated steels for sheet metal forming applications. Key Eng Mater 767: 223-231 (2018)

[25] Tian X F, Bhushan B. A numerical three-dimensional model for the contact of rough surfaces by variational principle. J Tribol 118(1): 33-42 (1996)

[26] Korzekwa D A, Dawson P R, Wilson W R D. Surface asperity deformation during sheet forming. Int J Mech Sci 34(7): 521-539 (1992)

[27] Kayaba T, Kato K. Experimental analysis of junction growth with a junction model. Wear 51(1): 105-116 (1978)

[28] McFarlane J S, Tabor D. Relation between friction and adhesion. Proc R Soc London Series A 251: 244-253 (1950)

[29] Courtney-Pratt J S, Eisner E. The effect of a tangential force on the contact of metallic bodies. Proc R Soc London Series A 238: 529-550 (1957) 
[30] Wilson W R D. Friction models for metal forming in the boundary lubrication regime. J Eng Mater Technol 113(1): 60-68 (1991)

[31] Challen J M, Oxley P L B. Slip-line fields for explaining the mechanics of polishing and related processes. Int $J$ Mech Sci 26(6-8): 403-418 (1984)

[32] Venema J, Hazrati J, Matthews D T A, Stegeman R A, van den Boogaard A H. The effects of temperature on friction and wear mechanisms during direct press hardening of $\mathrm{Al}-\mathrm{Si}$ coated ultra-high strength steel. Wear 406-407: 149-155 (2018)

[33] Venema J. Tribological interactions and modelling of friction in hot stamping. Ph.D. Thesis. Enschede (the Netherlands): University of Twente, 2019.

[34] Wang C, Hazrati J, de Rooij M B, Veldhuis M, Aha B, Georgiou E, Drees D, van den Boogaard A H. Temperature dependent micromechanics-based friction model for cold stamping processes. J Phys: Conf Ser 1063: 012136 (2018)

[35] Borsetto F, Ghiotti A, Bruschi S. Investigation of the high strength steel Al-Si coating during hot stamping operations. Key Eng Mater 410-411: 289-296 (2009)

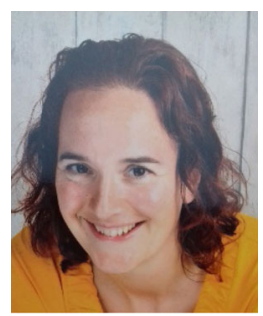

Jenny VENEMA. She received her Ph.D. degree in mechanical engineering from University of Twente, the Netherlands, in 2019.

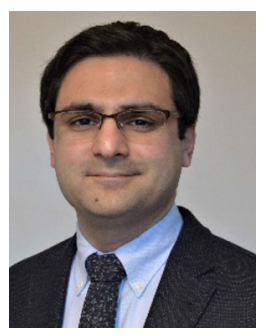

Javad HAZRATI. He received his Ph.D. degree in biomechanics from Eindhoven University of Technology, the Netherlands, in 2013. He is currently an assistant professor in

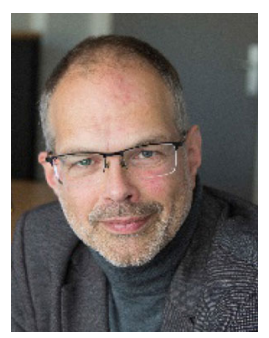

Eisso ATZEMA. He received his Ph.D. degree from the University of Twente in 1994, specialising in applied mechanics used in forming
[36] Windmann M, Röttger A, Hahn I, Theisen W. Mechanical properties of $\mathrm{AlXFeY}$ intermetallics in Al-base coatings on steel $22 \mathrm{MnB}_{5}$ and resulting wear mechanisms at presshardening tool steel surfaces. Surf Coat Technol 321: 321-327 (2017)

[37] Tabor D. The hardness of solids. Rev Phys Technol 1(3): 145-179 (1970)

[38] Bhushan B. Contact mechanics of rough surfaces in tribology: multiple asperity contact. Tribol Lett 4: 1-35 (1998)

[39] Saha P K, Wilson W R D. Influence of plastic strain on friction in sheet metal forming. Wear 172(2): 167-173 (1994)

[40] Timsit R S, Pelow C V. Shear strength and tribological properties of stearic acid films - part I: On glass and aluminum-coated glass. J Tribol 114(1): 150-158 (1992)

[41] Kato K, Hokkirigawa K. Abrasive wear diagram. In Proc Eurotrib '85, $4^{\text {th }}$ European Tribology Congress, Ecully, France, 1985.

[42] Hokkirigawa K, Kato K. An experimental and theoretical investigation of ploughing, cutting and wedge formation during abrasive wear. Tribol Int 21(1): 51-57 (1988)

Since 2005, she has been a principal researcher in the application department at Tata steel. Her research interests are tribological aspects during forming processes of steel.

nonlinear solid mechanics, University of Twente, the Netherlands. His research interests include friction and wear in material forming and modeling manufacturing processes related to material deformation.

technology. He has been working in forming technology at Tata Steel looking at supporting customers in processing the steel. 


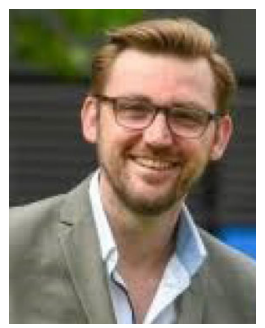

David MATTHEWS. He received his Ph.D. degree in applied physics and mathematics from the University of Groningen, the Netherlands, in 2008. Following nine years in industry as a principal researcher at

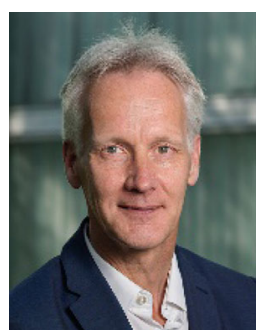

Ton van den BOOGAARD. He received his Ph.D. degree in mechanical engineering from the University of Twente in 2002. Since 2012, he has led the Chair Nonlinear
Tata Steel, he is now an associate professor in surface design and engineering at the University of Twente, the Netherlands. His research interests surround the design and manufacture of surfaces for a wide range of applications and environments.

Solid Mechanics and was appointed a full professor in 2015 at the same university. His research interests include mechanics of forming processes, computational material modelling, and process optimization. 